\section{THE ARTIFICIAL KIDNEY IN MALARIA AND BLACKWATER FEVER}

BY

\section{R. C. JACKSON, M.R.C.S., F.R.C.P.Ed.}

Air Commodore; Officer-in-Charge, Medical Division and Renal Unit, Princess Mary's R.A.F. Hospital, Halton, Bucks

AND

\section{A. W. WOODRUFF, M.D., Ph.D., F.R.C.P.} D.T.M.\&H.

Wellcome Professor of Clinical Tropical Medicine, University of London

Acute renal failure is one of the complications which for generations has been most dreaded in severe malaria and blackwater fever (Fairley et al., 1961). Maegraith (1944) pointed out that the mortality rate in blackwater fever was 20 to $25 \%$, and that approximately half these deaths resulted from renal failure. The use of the artificial kidney is a logical development in the management of renal failure occurring in severe Plasmodium falciparum infections with or without blackwater fever. To the best of our knowledge there are no reports in the literature of the use of an artificial kidney in malarial renal failure. We report the histories of four patients, three of whom were treated with the aid of an artificial kidney (Kolff twin-coil); two of these had severe cerebral malaria. A fourth patient's details are included, although he was not dialysed, because the history illustrates many points in the management and movement of these patients.

\section{Case 1}

An American civil airline pilot aged 36 had been flying regularly between the United States, West Africa, South Africa, and Great Britain for 18 months, during which period he had taken prophylactic antimalarial drugs only on one or two occasions. Ten days before admission he had developed headache, malaise, nausea, and a fever; however, five days later he piloted his airliner across the Atlantic and on arrival in London his symptoms became more severe. A diagnosis of influenza was made and he was treated with aspirin and bed rest for five days, during which time he remained febrile; his condition deteriorated, however, and because of some disorientation be was admitted to a general hospital on July 22, 1960. Here for the first time malaria was considered, and examination of blood films revealed a very heavy infection with $\boldsymbol{P}$. falciparum, approximately 1 in 10 of the red blood cells being parasitized.

At 2 p.m. on the day of admission he was given quinine hydrochloride $10 \mathrm{gr}$. (600 mg.) orally and $10 \mathrm{gr}$. (600 mg.) intravenously. In spite of this treatment his condition continued to deteriorate and after three hours he became comatose. Eighteen hours later, when one of us (A. W. W.) was first consulted, he was given an intravenous injection of $200 \mathrm{mg}$. (base) of chloroquine sulphate, an amount which was repeated by the same route six hours later. During the next 48 hours his temperature subsided and his coma appeared to become lighter-initially he had been deeply comatose with eyes everted and stertorous breathing-and he gagged and responded to his name. On the day after admission he was incontinent, but $240 \mathrm{ml}$. of urine had been measured, and his blood urea estimated at this time was $90 \mathrm{mg}$. $/ 100 \mathrm{ml}$. During the next 48 hours his daily urine output remained about $200 \mathrm{ml}$. and the blood urea rose to $224 \mathrm{mg} . / 100 \mathrm{ml}$.

The next day, July 26, which was regarded as the fifth day of renal failure, he was transferred to the Renal Unit, Princess Mary's R.A.F. Hospital, Halton. He remained unconscious but could be roused with difficulty; the blood urea was $356 \mathrm{mg} / 100 \mathrm{ml}$., haemoglobin $8.5 \mathrm{~g} . / 100 \mathrm{ml}$. (60\% Haldane), and serum bilirubin $3.5 \mathrm{mg} . / 100 \mathrm{ml}$. The first dialysis, which was performed on the sixth day of renal failure, improved his clinical state. The effects of eight dialyses on the blood urea and serum potassium values are shown in Fig. 1, where the daily urine output is also recorded. No further malarial parasites were found in the blood after the first intravenous injection of chloroquine. Because of the profound katabolic response, comparable with that of patients in renal failure following trauma, it was thought the severe malaria must have caused widespread tissue necrosis. A tracheostomy was performed on the day between the fourth and fifth dialyses, because of the

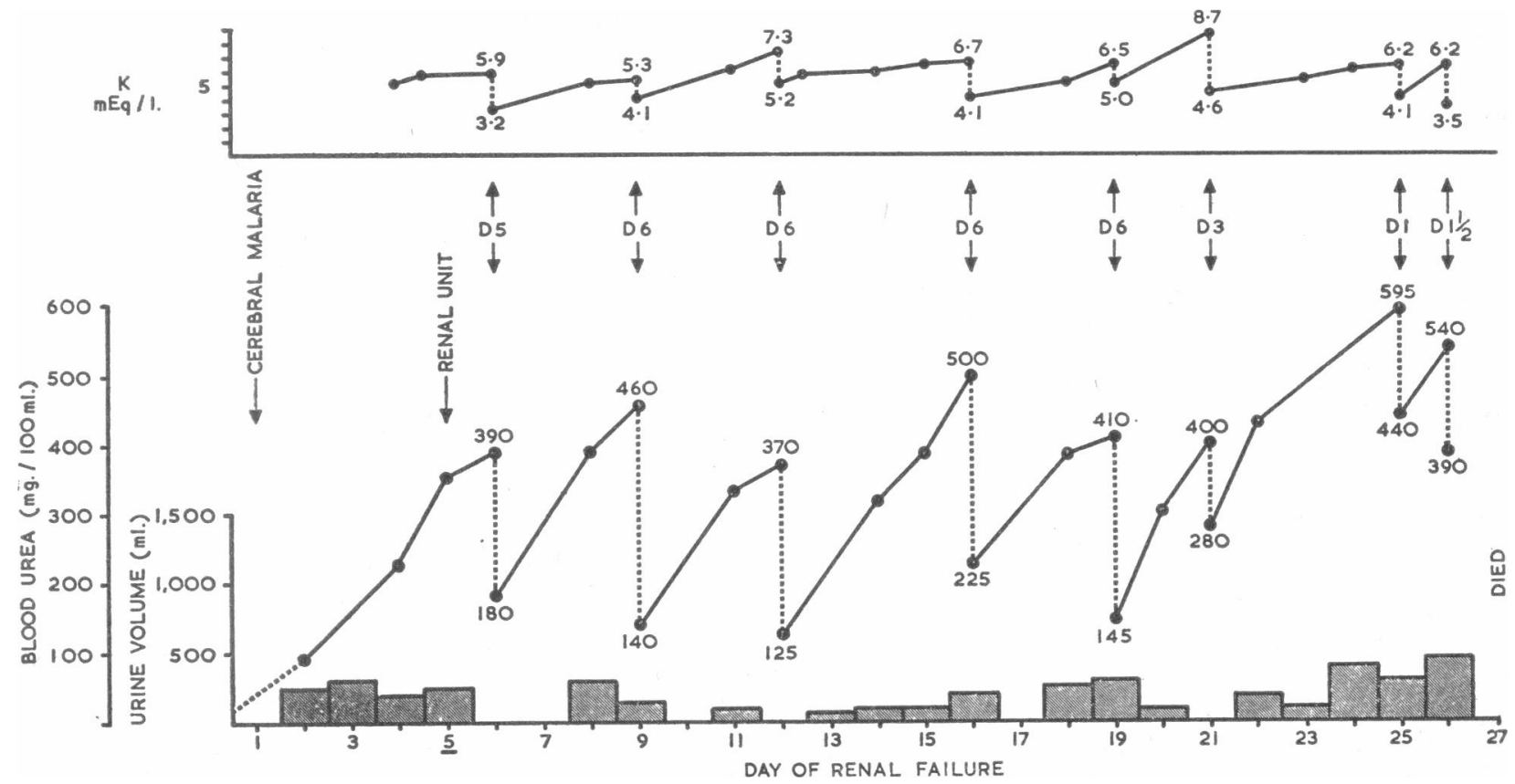

Fig. 1.-Case 1. Effects of eight dialyses on the blood urea and serum potassium values. Patient was in coma throughout the period shown. Tracheostomy was performed on 17 th day of renal failure. Death occurred on the 27 th day. D6=Dialysis in hours. 
pooling of secretions in the pharynx and the increasing depth of coma. Seven days later his condition deteriorated rapidly with the occurrence of frequent hypotensive episodes and later positive-pressure breathing became essential. $\mathrm{He}$ died on August 17, the 27th day of renal failure, before the onset of a diuresis.

\section{Post-mortem Findings}

At necropsy (Wing Commander J. K. Mason) the left lung was comparatively dry, but there was moderate oedema of the right; the small and large intestines contained sanguineous material throughout their length and the mucosa appeared gangrenous, particularly in the jejunum and sigmoid colon (Fig. 2). The left kidney weighed $260 \mathrm{~g}$.

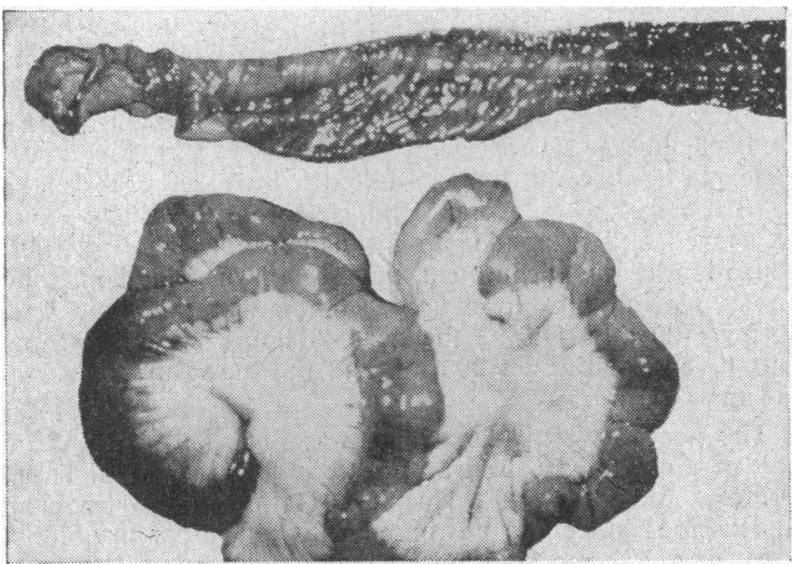

Fig. 2.-Case 1. Necropsy photograph showing the necrosis and gangrene of the sigmoid colon, mucosal aspect, and the small intestine, particularly the jejunum, which can be seen at the lower left-hand corner of the figure. (From Ektachrome transparency.)

and the right $200 \mathrm{~g}$., both were dark in colour and there was almost complete obliteration of the cortico-medullary boundary.

\section{Histology}

In the lower lobes of the lungs there was some purulent exudate but remarkably little evidence of bronchopneumenia. There were areas of necrosis and inflammation of the large bronchi, where masses of organisms could be seen. There was widespread enterocolitis, most pronounced in the large bowel, and there could be no doubt that this was an ante-mortem phenomenon. The liver showed widespread fatty change of the parenchymal cells. All the Kupffer cells were heavily impregnated with malarial pigment. The spleen was almost black with malarial pigment; it was engorged with red blood cells, and the Malpighian bodies were very prominent. In the kidneys the appearances of the glomeruli were within normal limits though there was occasional sclerosis associated with small areas of pyelonephritis. The tubules contained large amounts of pigment and albuminous casts, but the epithelium was remarkably normal. The picture was that of renal tubular necrosis which was healing. The adrenal cortices were virtually devoid of lipoid.

Professor Blackwood, at the National Hospital for Nervous Diseases, Queen's Square, kindly examined sections of the organs of the central nervous system and reported: "In the section of the cerebral cortex there is a moderate loss of nerve cells from the cortex, but the main changes are in the white matter, where there is a generalized increase of astrocytes together with small foci of myelin destruction and collections of fat-containing phagocytes. We cut frozen sections of the frontal, parietal, occipital cortex, and white matter and found similar changes in both cortex and white matter. In the basal ganglia there is also neuronal loss. In the brain-stem I could not find any definite changes."

The pituitary showed widespread presence of shock cells. The appearances in the central nervous system suggested a generalized anoxia that presumably resulted from the original cerebral infection, which was uncontrolled for a long time. It is extremely unlikely that recovery from such a degree of damage would have been possible. The cerebral damage, which was the cause of death, was complicated by a terminal enterocolitis and a terminal severe bronchitis with early bronchopneumonia. These probably resulted from ultimate break-through of antibiotic-resistant organisms. In addition there appeared to be evidence of adrenal cortex exhaustion.

\section{Case 2}

An able seaman, Royal Navy, aged 19, serving on board one of H.M. ships in the Indian Ocean, spent some days ashore in Mombasa, Kenya. He took proguanil hydrochloride ("paludrine") only occasionally for malaria prophylaxis. On February 1, 1961, when at sea again, he felt ill and suffered severe headaches with aches and pains in his limbs, but did not report sick until February 3, when he was admitted to the ship's sick-bay, where a pyrexia of $104^{\circ} \mathrm{F}\left(40^{\circ} \mathrm{C}\right.$.) was recorded. On February 5 blood films showed the presence of parasites of $P$. falciparum, so treatment was started immediately with oral chloroquine sulphate $600 \mathrm{mg}$. (base) followed by $300 \mathrm{mg}$. of base daily. The small amount of urine passed on this day was reported as " thick, dark brown in colour, with a heavy cloud of protein; the deposit contains a few red blood cells and much amorphous debris." Because of the clinical evidence of blackwater fever and a deterioration in his condition caused by vomiting, drowsiness, and persistent oliguria, he was transferred by helicopter to hospital in Bahrein on February 7.

On admission there his haemoglobin was $9.9 \mathrm{~g} . / 100 \mathrm{ml}$. (71\% Haldane), P.C.V. $32 \%$, blood urea $160 \mathrm{mg} .1100 \mathrm{ml}$, and serum bicarbonate $16 \mathrm{mEq} / 1$., and examination of fresh blood films showed no further evidence of parasites. He was anuric for two days and passed $100 \mathrm{ml}$. of urine on February 9. Because this amount was thought to herald the return of renal function and because of the belief, still held in many quarters, that patients with blackwater fever must not be moved, it was decided on that day, which was also the ninth day of renal failure, that he should not be transported for one to two weeks. However, his clinical condition continued to deteriorate, the renal failure persisted, and his blood urea rose to $260 \mathrm{mg} . / 100 \mathrm{ml}$. Consequently aeromedical evacuation to the United Kingdom for admission to the renal unit was arranged. He left Bahrein by air on February 13, and later that day landed at Aden, where his blood urea was recorded as $500 \mathrm{mg} / 100 \mathrm{ml}$. Unfortunately his condition became worse and he died in the aircraft three hours' flying-time from his destination, Royal Air Force Station Lyneham, in Wiltshire. Fig. 3 illustrates these events and the progress of the renal failure.

\section{Post-mortem Findings}

At necropsy, eleven hours after death (Squadron-Leader P. J. Stevens), death was found to be caused by pulmonary oedema and acute heart failure due to acute renal failure complicating malignant tertian malaria and blackwater fever.

Lungs: The pleural cavities each contained about $200 \mathrm{ml}$. of fluid. The trachéa and bronchi were full of frothy watery fluid and the lungs were grossly oedematous and congested ; confirmed microscopically. There was no evidence of bronchopneumonia. The cardiovascular system was normal histologically. Alimentary system: The liver (2,530 g.) was dark and congested in the central veins and sinusoids. Central nervous system: The brain $(1,400$ g.) was oedematous and the vessels were congested, but no evidence of infarction could be seen. Kidneys: Both organs were swollen and weighed $310 \mathrm{~g}$. and $360 \mathrm{~g}$. The glomeruli showed only slight congestion of the capillaries. Tubules : The proximal, distal, and collecting tubules all showed evidence of parenchymatous change with necrosis of the 


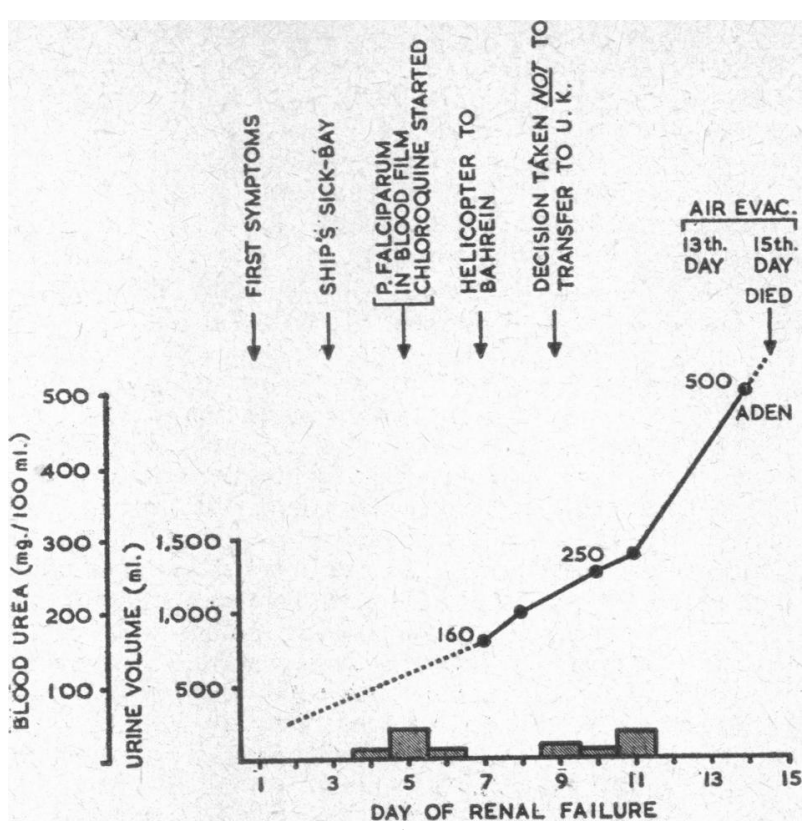

FIG. 3.-Case 2. Showing the profound oliguria, blood-urea values, and record of events culminating in aeromedical evacuation from the 13th to 15 th day of renal failure. The patient died before reaching the United Kingdom. There are no records of the urine output during the 1st to 3rd days and 12th to 15th days.

epithelium, ranging from hydropic degeneration to necrosis and ultimate regeneration. There was formation of hyaline casts not only in the tubules but in some areas in the adjacent interstitial tissue. Many of the collecting tubules contained extravasated red cells as well as haemoglobin casts.

\section{Case 3}

A lance-corporal, aged 24, in the Royal Army Service Corps had spent nine months in the Cameroons, West Africa, and had taken proguanil hydrochloride only sporadically for malarial prophylaxis. On May 29, 1961, he departed on a troopship for the United Kingdom; on June 2 he complained of headaches and symptoms similar to influenza and was admitted to the ship's sick-bay with that diagnosis. He had an intermittent pyrexia up to $104^{\circ}$ F. $\left(40^{\circ} \mathrm{C}\right.$.), and within 24 hours diarrhoea, vomiting, and generalized aches and pains developed. These symptoms continued unabated until marked conjunctival icterus was noted on June 7 ; there were no comments on the urine volume up to this time. On June 8 examination of blood films revealed numerous parasites of $\boldsymbol{P}$. falciparum, and antimalarial treatment was commenced with chloroquine (base) $450 \mathrm{mg}$. by mouth and $200 \mathrm{mg}$. of base intravenously. On this day he passed $270 \mathrm{ml}$. of very dark urine, and it was obvious his condition was deteriorating. The troopship arrived in Las Palmas, Canary Islands, on June 10 to replenish with water, and on that day the patient was transferred ashore to the Seamen's Hospital, Las Palmas, where his blood urea was found to be $357 \mathrm{mg} . / 100 \mathrm{ml}$., serum potassium $5.8 \mathrm{mEq} / 1$, serum bilirubin $3.4 \mathrm{mg} .100 \mathrm{ml}$., haemoglobin 7.2 g. $/ 100 \mathrm{ml}$. (50\% Haldane), and P.C.V. $23 \%$. The urine contained urobilin and protein, and had a specific gravity of 1011. An urgent request was made to Royal Air Force Transport Command for aeromedical evacuation to the United Kingdom and this was answered quickly, with the result that the patient was admitted to the renal unit at Halton on June 11, exactly 24 hours after transfer was requested.

He travelled well by air, his clinical condition having improved slightly, but he had troublesome hiccup, was dehydrated and icteric. The B.P. was $110 / 50$, the spleen was palpable, and in blood films ring forms with an occasional gametocyte of $\boldsymbol{P}$. falciparum were present. The serum bilirubin was $6.5 \mathrm{mg} . / 100 \mathrm{ml}$. and remained elevated for a further six days. The blood urea had risen to $370 \mathrm{mg} .1100 \mathrm{ml}$.; the serum potassium was $4.3 \mathrm{mEq} / 1$, serum sodium $103 \mathrm{mEq} / 1$., serum chloride $87 \mathrm{mEq} / 1$., and serum bicarbonate $19 \mathrm{mEq} / \mathrm{l}$. The haemoglobin was $5.8 \mathrm{~g} . / 100 \mathrm{ml}$. (42\% Haldane) and P.C.V. $20 \%$. There were no abnormal constituents in the urine apart from $0.4 \mathrm{~g}$. of protein per litre, the specific gravity being 1010 .

Dialysis was performed the next day, and this produced a considerable improvement in his clinical state, his haemoglobin being raised to $7.1 \mathrm{~g} . / 100 \mathrm{ml}$. ( $50 \%$ Haldane) at the same time. On this day (June 12), and probably the eleventh day of renal failure, a diuresis began. Fig. 4 shows the subsequent biochemical progress: persistent diarrhoea was the reason for the relatively low serum potassium values.
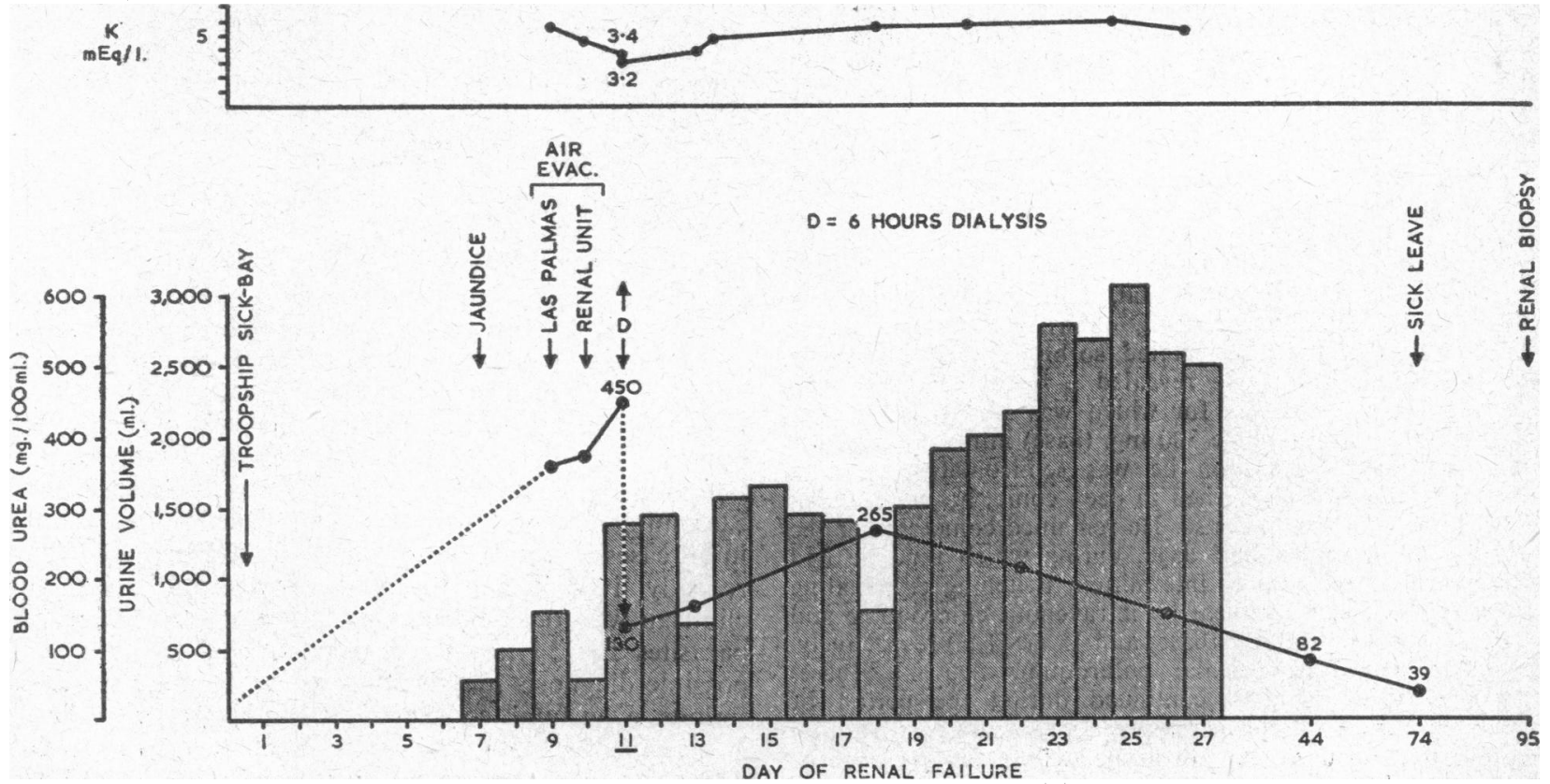

Fig. 4.-Case 3. Biochemical values and urine volumes are shown. The low serum potassium figures were the result of severe diarrhoea. There was no record of urine volumes from the 1st to 6th days of renal failure. Dialysis was performed on the 11th day, when a diuresis also started. 
Because of the parasitaemia present on admission he was given 20 gr. $(1.3 \mathrm{~g}$.) of quinine hydrochloride intravenously over nine hours and a daily oral dose of $300 \mathrm{mg}$. of chloroquine (base) for four days, and with this treatment the parasites disappeared from the peripheral blood in 24 hours. Apart from a left-lower-lobe pneumonia his recovery was uneventful, but his blood urea remained raised for 74 days before returning to normal.

A needle biopsy of the right kidney was performed (R. C. J.) 95 days after the onset of renal failure, and this showed that tubular necrosis was still present (Fig. 5); at

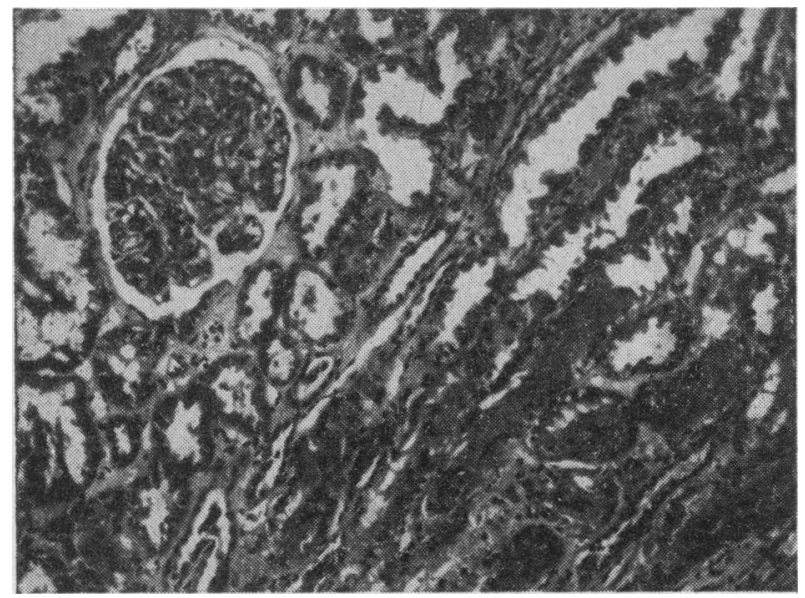

Fio. 5.-Case 3. Renal biopsy on the 95th day of renal failure. The persistence of tubular necrosis is evident; the glomeruli are within normal limits. (H. and $E$. $\times 100$.)

this time the urine urea had risen to $1.5 \mathrm{~g} . / 100 \mathrm{ml}$. and the proteinuria was $0.7 \mathrm{~g} . / 1$. In October he was returned to the care of the Army, when he was symptomless, having gained $19.8 \mathrm{lb}$. $(9 \mathrm{~kg}$.) in weight. His haemoglobin was 14.8 g./110 ml. (103\% Haldane), but he had still slight impairment of renal function, which it was anticipated would return to normal within a few months.

\section{Case 4}

A private soldier, aged 22, serving in Aden, spent two weeks' leave in Mombasa, Kenya, returning to Aden on November 4. 1961. He was supplied with an adequate number of tablets of proguanil hydrochloride by his unit for malarial prophylaxis in Mombasa. Unfortunately he didn't take any of the tablets.

On November 20 he complained of malaise and shivering, then started to vomit occasionally. Because of the onset of severe headaches he reported to his unit doctor on November 22 and again on November 23. However, by that evening his skin had become icteric and he was admitted to the Royal Air Force Hospital, Aden, with a provisional diagnosis of infective hepatitis. During November 24 he became drowsy and disorientated, so blood films were taken at 10.30 p.m., and these revealed a heavy infection with $P$. falciparum, treatment for which was started at 11 p.m. with chloroquine sulphate $300 \mathrm{mg}$. (base) intravenously. At the time of the injection he was semicomatose, and at 6.30 a.m. the next day, when in deep coma, he had a series of epileptiform convulsions. He remained comatose for the ensuing three and a half days, during which time he had three further episodes of intermittent twitching culminating in epileptic fits. Treatment by intravenous chloroquine and quinine totalling $600 \mathrm{mg}$. (base) and $15 \mathrm{gr}$. $(1 \mathrm{~g}$.) respectively, together with intramuscular chloroquine $200 \mathrm{mg}$. (base) given eight-hourly, had continued during the period of unconsciousness. Blackwater fever and acute renal failure had been diagnosed. the former based on the presence of methaemoglobinuria revealed spectroscopically on November 25 . the latter by the profound persistent oliguria and rising blood urea.
Because of these serious complications and his gradual return to consciousness, he was transferred to the United Kingdom on November 28 by Royal Air Force aeromedical evacuation. His haemoglobin was 5.5 g./100 ml. (39\% Haldane) on the day of transfer before leaving Aden.

He was admitted to the renal unit at 1.45 p.m. on November 29, which was calculated to be the seventh day of renal failure, having travelled well with little change in his condition. Absence of further haemolysis was indicated by a maintained haemoglobin value during the 3,800-mile (6,115-km.) journey.

On admission he was still disorientated, pale, mildly icteric, and hyperventilating. Examination revealed a pyrexia of $100^{\circ} \mathrm{F} .\left(37.8^{\circ} \mathrm{C}\right.$.), which reached a maximum of $102^{\circ} \mathrm{F}$. $\left(38.9^{\circ} \mathrm{C}\right.$.), a distended tympanitic abdomen but no palpable spleen, and a stiff left knee-joint which was painful when moved. There was a large recent haemorrhage in the left fundus which subsequently resolved in 11 days. The blood urea was $350 \mathrm{mg} / 100 \mathrm{ml}$., serum potassium $4.8 \mathrm{mEq} / 1$., serum bicarbonate $16 \mathrm{mEq} / 1$., serum sodium $118 \mathrm{mEq} / 1$., and serum chloride $87 \mathrm{mEq} / \mathrm{l}$. There was a severe anaemia but no change in the haemoglobin, which was $5.6 \mathrm{~g} . / 100 \mathrm{ml}$. (40\% Haldane); the P.C.V. was $19 \%$. A bilirubinaemia of $1.8 \mathrm{mg} . / 100 \mathrm{ml}$. was present : this increased to $3.8 \mathrm{mg}$./ $100 \mathrm{ml}$. before returning to normal on the sixteenth day. Blood was taken for routine culture on admission, a coagulase-positive staphylococcus being isolated in two bottles within 48 hours. No malarial parasites were seen in blood films. Because of the tender left knee-joint and the pyrexia he was given a broad-spectrum antibiotic immediately, and later penicillin was added when the results of the staphylococcus sensitivities were available. The kneejoint gradually became more painful and swollen until December 5 , when aspiration of the joint produced $70 \mathrm{ml}$. of thin sterile pus.

He was dialysed the day after admission: Fig. 6 depicts his subsequent biochemical progress. Fortunately the septicaemia was controlled early ; however, it was the cause of the severe katabolism which required three dialyses to keep him alive until a diuresis started on the nineteenth day of renal failure. A further complication occurred about the twenty-fourth day of renal failure. when he developed malaise, increasing jaundice, and pain in the right hypochondrium. This phase lasted about seven days and was accompanied by a bilirubinaemia rising to a maximum of $7 \mathrm{mg} . / 100 \mathrm{ml}$. The alkaline phosphatase reached a value of 73 King-Armstrong units. which confirmed the diagnosis of transient biliary-tract obstruction because of a possible pigment stone or thick biliary sediment. His subsequent progress to recovery was uneventful.

\section{Discussion}

Among the many important points raised by the histories of these four patients one, which is common to all, is the laxity concerning malaria prophylaxis. Clearly, tragedies that are easily avoidable are still occurring from this cause, and it cannot be emphasized too strongly that a visit of even 24 hours' duration to an area in which $P$. falciparum infection is endemic necessitates the institution of one of the standard malaria prophylactic regimes. These cases further illustrate the importance of suspecting malaria and of examining a blood film for malaria parasites immediately in all cases in which the patient is febrile and has either recently lived in a malarial area or visited one. The clinician who delays the examination of blood films for parasites for 24 hours after considering malaria as a possible diagnosis may find his action has had the most serious, even fatal, consequences for his patient. There is perhaps no other disease in which delay in starting treatment may cause what is otherwise an easy therapeutic exercise to become one in which the result is hopeless. 

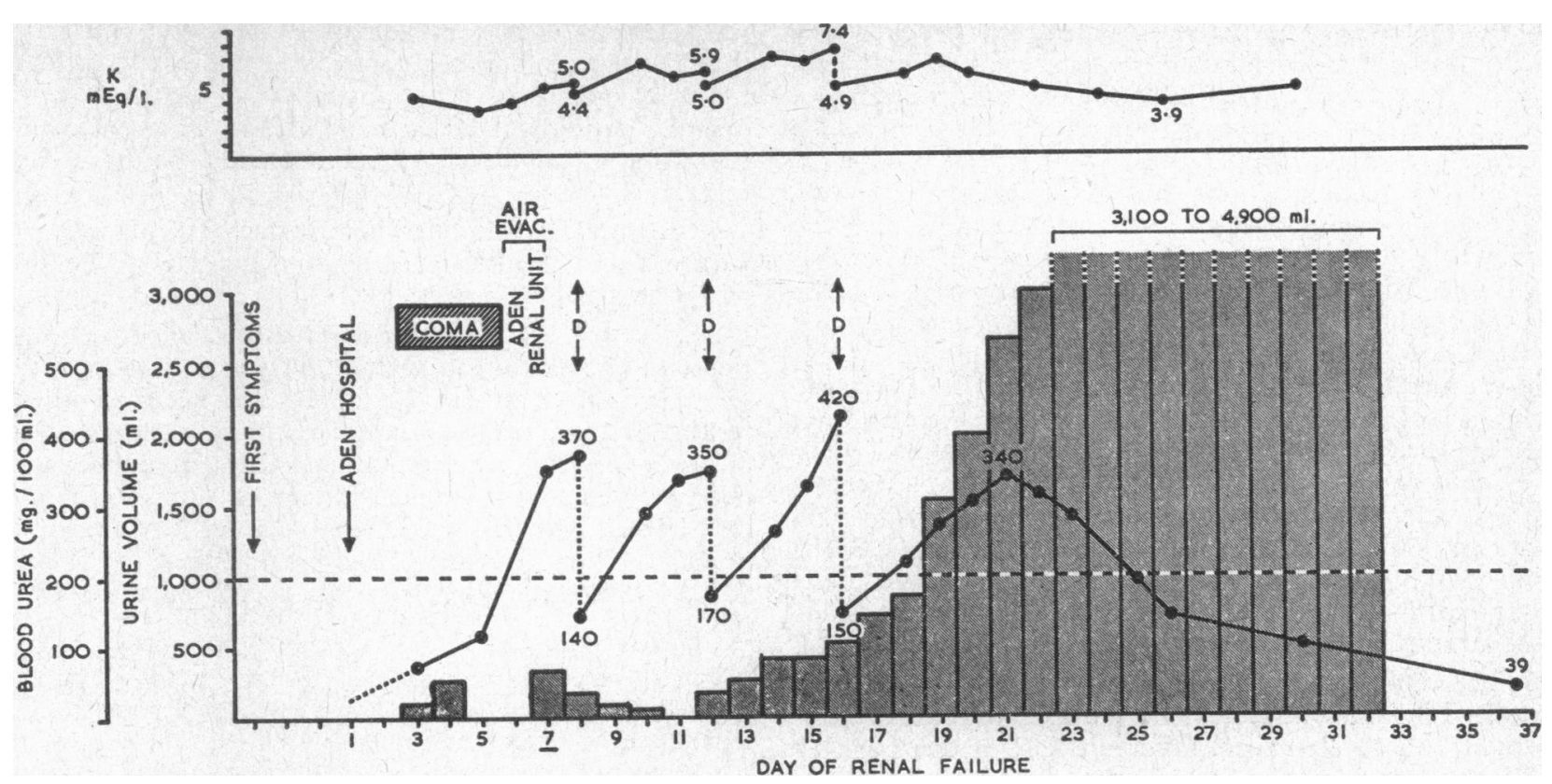

Fig. 6.-Case 4. Biochemical values and results of three dialyses on the 8th, 12th, and 16th days of renal failure are shown. Aeromedical transfer occurred on the 6th and 7th days following three and a half days of coma. A diuresis started on the 19th day, the maximum urine volume in the next 14 days being $4,900 \mathrm{ml}$.

The importance of early effective treatment is further emphasized by the way in which the cerebral cortex in the first patient had been irreversibly damaged by an infection which was eradicated without difficulty once adequate treatment was administered. If it had not been for this fact we believe recovery would have been possible hecause the renal lesion was healing. It appears. however, that death was primarily the result of the cerebral damage presumahly caused by anoxia following the very severe malarial infection. The profound kataholic response with the rapid rise of the blood urea in this patient was caused by tissue destruction resulting from the enterocolitis and gangrenous state of the bowel. This may well have been associated finally with an infection by antibiotic-resistant organisms, but in view of the necropsy evidence of kidney. liver, and severe cerebral damage. all presumably caused by anoxia, it appears probable that a similar cause resulted in necrosis of the bowel wall with the later onset of infection of the necrosed tissue spreading from the lumen of the bowel.

In contrast, the second patient died from the effects of the renal failure and not directly because of the malaria. The situation at necropsy was typical of severe unrelieved uraemia and overhydration, which can now be reversed by the use of an artificial kidney. This would have been possible in this case had his transfer to the renal unit not been delayed until the thirteenth day of renal failure.

The acute renal failure which is caused by malaria with or without blackwater fever is similar to that caused by many other varied clinical conditions, both medical and surgical. The renal lesion is a tubular necrosis and therefore reversible. with the possibility of complete healing and the return of normal kidney function. Maegraith and Findlay (1944) and Maegraith (1944) described the clinical and pathological findings in blackwater fever with renal insufficiency, and discussed the reasons why they believed the renal failure was caused by a reduced renal blood flow and anoxia aggravated by the malarial infection. They refuted the then current belief that the oliguria was caused by the blockage of the tubules by debris and the products of red-blood-cell haemolysis. These opinions have been confirmed and the theory that blockage of the tubules with casts. debris, or crystals was the sole cause of the renal failure is now untenable.

Histological evidence obtained in this study confirms that tubular necrosis is responsible for the acute renal failure following severe $\boldsymbol{P}$. falciparum malaria and blackwater fever. In blackwater fever severe haemolysis is invariable, but all such patients do not necessarily develop acute renal failure. Maegraith and Findlay (1944) pointed out that the majority of patients with blackwater fever have some nitrogen retention. Undoubtedly, in some of these this is caused by a prerenal failure associated with dehydration, which can be easily corrected. It is of vital importance that there should be little delay in diagnosing the true renal failure (tubular necrosis), because the therapy for it is exactly opposite to that of the oliguria of dehydration.

The appreciation of the definition of oliguria is essential in the early recognition of the onset of acute renal failure. The criteria should be that renal failure must be assumed if the patient persists in passing a urine volume of less than $760 \mathrm{ml}$. per 24 hours $(0.5 \mathrm{ml}$./ min.) with a specific gravity lower than 1016. Some patients will have a short oliguric phase of a few days and will recover provided the usual modified Bull's regime of a carbohydrate solution is given without electrolytes, protein, or fat (Parsons and McCracken, 1959 ; Jackson et al., 1960), although in tropical climates three or four times the normal fluid allowance of $500 \mathrm{ml}$. for insensible loss may be necessary. However, others will continue to be oliguric or occasionally anuric and will die in severe uraemia, as many have done in the past, unless they are moved early enough to a special unit where treatment with an artificial kidney is available, this fact being emphasized in the history of the second patient. 
In the past it has been accepted that patients with acute renal failure following severe malaria or blackwater fever were nursed best with the minimal amount of movement and transport from the place at which the illness began. The main reasons put forward for this view have been the fear of deterioration in the patient's condition from the renal and haemolytic aspects. For some years now experience has shown that patients with renal failure have travelled satisfactorily considerable distances by air in the oliguric phase (Jackson, 1962), and Cases 3 and 4 in this series demonstrate that increased haemolysis, as evidenced by significant deterioration in the haemoglobin and haematocrit values, was not a feature in spite of their movement thousands of miles by air. Until recently there was no advantage to be gained by moving such patients, because haemodialysis was not available. Since the advent of the artificial kidney there exists the possibility of saving many of these patients, as illustrated by the successful outcome in Cases 3 and 4 .

These facts necessitate a revision of the old concepts concerning the movement of patients with blackwater fever who develop renal failure. Most of them will be situated considerable distances from specialized centres, but there should be no bar to their transfer provided they are transported early enough. If the oliguria, as defined above, persists longer than three days, then arrangements should be made as quickly as possible to transport the patient by air to a centre with facilities for haemodialysis. The short period of three days is recommended because even under ideal conditions it may take a further three days before the specialized unit is reached. This situation will no doubt improve in the future when artificial-kidney centres are established in areas where $\boldsymbol{P}$. falciparum malaria is prevalent.

The possibility now of patients developing malaria in the United Kingdom and in other countries in temperate zones is by no means remote because of the rapidity and frequency of air transport from malarial regions, particularly the African continent. This has been our experience and that of many other clinicians. The development of acute renal failure in some of these patients and their improved chances of survival with modern therapy should be borne in mind.

\section{Summary}

Of four patients (one civilian and three Service men) who developed acute renal failure complicating $P$. falciparum malaria and blackwater fever, two had severe cerebral malaria, from which one recovered. Of the remaining two, one died during air transit a few hours before admission and the other patient survived.

Haemodialysis was performed on three of the patients. One patient, a civil airline pilot, became ill in the United Kingdom; the other three were evacuated by air from Bahrein, Aden, and West Africa via Las Palmas.

The dangers of inadequate malaria prophylaxis and delay in starting treatment in malaria are stressed. Tubular necrosis is confirmed by renal biopsy and necropsy as the lesion causing the renal failure which follows severe $P$. falciparum malaria and blackwater fever. Attention is drawn to its reversibility and to the importance of its early recognition.

The concept that patients with blackwater fever should not be moved must be revised if those with renal failure are to have every chance of survival. If acute renal failure is present for three days arrangements should be made for transfer to a centre with facilities for haemodialysis. The possibility of patients with malaria developing acute renal failure in the United Kingdom or temperate climates should be borne in mind.

It is probable that this is the first record of patients with malarial renal failure being managed with the aid of an artificial kidney.

Addendum.-Since submitting this article for publication two further patients with $\boldsymbol{P}$. falciparum malaria with unrecognized acute renal failure have been admitted to R.A.F. Hospital, Aden, in a moribund state because of severe uraemia, metabolic acidosis, and pulmonary oedema. They died within 36 hours of admission from the effects of the acute renal failure. We thank Squadron Leader A. M. Kingon, medical specialist, R.A.F. Hospital, Aden, for the details of these two patients.

We thank Flight Lieutenants N. V. Bunker, W. J. Elder, and H. McDonnell ; Flight Officer M. O'Connor, P.M.R.A.F.N.S., and her nursing staff for their efficient treatment and nursing care ; Air Commodore W. P. Stamm and his staff at the R.A.F. Institute of Pathology and Tropical Medicine for their able assistance; and Wing Commander J. K. Mason for the photomicrograph. We would like to pay tribute to the high standard of efficiency of the Royal Air Force Transport Command aeromedical teams, both aircrew and medical, in transporting these very ill patients. We thank the Director-General Medical Services, Royal Air Force, for permission to publish.

REFERENCES

Fairley, N. H., Woodruff, A. W., and Walters, J. H. (1961). Recent Advances in Tropical Medicine, 3rd ed. Churchill, London.

Jackson, R. C. (1962). Brit. J. clin. Pract., 16, 304.

Bunker, N. V. D., Elder, W. J., and Joekes, A. M. (1960). Brit. med. J., 2. 1909 .

Maegraith, B. G."(1944). Trans. roy. Soc. trop. Med. Hyg., 38, 1. and Findlay, G. M. (1944). Lancet, 2, 403.

Parsons, F. M., and McCracken, B. H. (1959). Brit. med. J., 1, 740 .

The British Standards Institution's committee on hypodermic syringes states that "the use of the word 'record" in connexion with hypodermic syringes has for some years caused confusion and has now become embarrassingly ambiguous," and it considers that the word "record" should be restricted to a single meaning, particularly as syringes with the Luer fitting are now becoming increasingly known in the United Kingdom and syringe users are therefore less familiar with the use of the term "record." In the past the term "record" has been used to define a syringe nozzle having the old Continental or $10 \%$ taper and the word originated from the original German makers. The B.S.I. committee considers it is in this connexion only that the word should be used and not in its secondary sense, meaning a type of syringe-that is, a syringe of a construction that includes a glass barrel with metal fittings and purely metal piston. If this secondary meaning were perpetuated it would be possible to describe a syringe as "record syringe with Luer nozzle," which is most undesirable. The B.S.I. committee therefore recommends that the use of the word "record" be from now on confined to describing the taper of the nozzle. The Luer conical fitting (6\% taper) is specified in British Standards for hypodermic equipment. The B.S.I. committee unanimously recommends that this fitting be generally adopted for hypodermic equipment in the United Kingdom because of the greater strength of the syringe nozzle and the better grip attained between the syringe nozzle and the needle mount as compared with the "record" I.P.B. fitting. 